\title{
An automated gas chromatography time-of-flight mass spectrometry instrument for the quantitative analysis of halocarbons in air
}

\author{
F. Obersteiner, H. Bönisch, and A. Engel \\ Institute for Atmospheric and Environmental Science, Goethe University Frankfurt, Frankfurt, Germany \\ Correspondence to: F. Obersteiner (obersteiner@iau.uni-frankfurt.de)
}

Received: 16 July 2015 - Published in Atmos. Meas. Tech. Discuss.: 14 September 2015

Revised: 13 December 2015 - Accepted: 28 December 2015 - Published: 25 January 2016

\begin{abstract}
We present the characterization and application of a new gas chromatography time-of-flight mass spectrometry instrument (GC-TOFMS) for the quantitative analysis of halocarbons in air samples. The setup comprises three fundamental enhancements compared to our earlier work (Hoker et al., 2015): (1) full automation, (2) a mass resolving power $R=m / \Delta m$ of the TOFMS (Tofwerk AG, Switzerland) increased up to 4000 and (3) a fully accessible data format of the mass spectrometric data. Automation in combination with the accessible data allowed an indepth characterization of the instrument. Mass accuracy was found to be approximately $5 \mathrm{ppm}$ in mean after automatic recalibration of the mass axis in each measurement. A TOFMS configuration giving $R=3500$ was chosen to provide an $R$-to-sensitivity ratio suitable for our purpose. Calculated detection limits are as low as a few femtograms by means of the accurate mass information. The precision for substance quantification was $0.15 \%$ at the best for an individual measurement and in general mainly determined by the signal-to-noise ratio of the chromatographic peak. Detector non-linearity was found to be insignificant up to a mixing ratio of roughly $150 \mathrm{ppt}$ at $0.5 \mathrm{~L}$ sampled volume. At higher concentrations, non-linearities of a few percent were observed (precision level: $0.2 \%$ ) but could be attributed to a potential source within the detection system. A straightforward correction for those non-linearities was applied in data processing, again by exploiting the accurate mass information. Based on the overall characterization results, the GC-TOFMS instrument was found to be very well suited for the task of quantitative halocarbon trace gas observation and a big step forward compared to scanning, quadrupole MS with low mass resolving power and a
\end{abstract}

TOFMS technique reported to be non-linear and restricted by a small dynamical range.

\section{Introduction}

The history of environmentally harmful airborne halocarbons and the need for monitoring them in the atmosphere goes back to the 1950s with the introduction of chlorofluorocarbons (CFCs) synthesized and promoted by Thomas Midgley (Midgley, 1937). The production of CFCs was banned by the Montreal Protocol in 1987 after highly rising emissions of CFCs and the subsequent discovery of the catalytic depletion of stratospheric ozone (Molina and Rowland, 1974) and the ozone hole (Farman et al., 1985). CFCs were replaced by partly halogenated hydrochlorofluorocarbons (HCFCs) and are nowadays replaced by a variety of hydrofluorocarbons (HFCs). HFCs do not destroy stratospheric ozone significantly (Ravishankara et al., 1994); nevertheless most of them are strong greenhouse gases with a global warming potential much larger than $\mathrm{CO}_{2}$ (Velders et al., 2005). The ongoing introduction of new compounds and their release to the atmosphere (e.g. Arnold et al., 2012; Vollmer et al., 2011) leads to the need not only to monitor known compounds but also to identify new compounds. In the attempt to extend site measurements to emission surveillance, promising approaches have been made by combining measurement data with inverse modelling (e.g. Keller et al., 2011; Lunt et al., 2015; Maione et al., 2008; Simmonds et al., 2015; Stohl et al., 2010).

In the early days of halocarbon measurement, the electron capture detector was the instrument of choice 
(Clemons and Altshuller, 1966). This choice moved to mass spectrometers later on as an additional dimension of information is added: molecule-specific fragmentation. Today, the most sophisticated instrumentation for the task is probably the Medusa GC-MS of the AGAGE (Advanced Global Atmospheric Gases Experiment) network described by Miller et al. (2008) with a quadrupole mass filter for detection. The Medusa systems have been applied for many investigations - from perfluorocarbons (Mühle et al., 2010), hydrocarbons (Grant et al., 2011) and nitrogen trifluoride (Arnold et al., 2012) to emerging HFCs just recently by Vollmer et al. (2015). In particular, quadrupole MS has been used by many others for halocarbon analysis (e.g. Grimsrud and Rasmussen, 1975; Sala et al., 2014; Simmonds et al., 1995) and sometimes also sector field MS (e.g. Laube et al., 2012; Lee et al., 1995). In contrast, TOFMS is much more widespread in other fields of research such as aerosol composition analysis (e.g. DeCarlo et al., 2006), measurements of volatile organic compounds (e.g. Graus et al., 2010) and proteomics (e.g. Bonk and Humeny, 2001). The big advantage of TOFMS over quadrupole MS and sector field MS is the intrinsic full mass range data acquisition without spectral skew. However, there were also two significant limitations to quantitative analysis with TOFMS observed in the past: limited dynamic range and non-linearity - e.g. as described by Emteborg et al. (2000), Rowland and Holcombe (2009) as well as Hoker et al. (2015) for the field of application of this work.

In this work, we go one step further from our first application of TOFMS for halocarbon analysis described in Hoker et al. (2015) using a BenchTOF-dx (Markes International Ltd, UK). A new GC-TOFMS system was set up including fully automated sample preconcentration and a Tofwerk EI-TOF model mass spectrometer with a significantly higher-than-nominal mass resolving power and data in a fully accessible data format. Technical descriptions regarding sample preparation, gas chromatography, mass spectrometry and data treatment are given in Sect. 2 of this paper. The presentation and discussion of characterization experiments and selected applications can be found in Sect. 3. The section is structured to go from basic parameters like mass accuracy (Sect. 3.1) over detection limits (Sect. 3.2) and measurement precision (Sect. 3.3) to non-linearities (Sect. 3.4) for which most aspects discussed before have to be considered. For quality assurance, we show results from a comparison to a reference instrument, a stateof-the-art GC-quadrupole MS (GC-QPMS), in Sect. 3.5.

\section{Technical description}

This section gives a technical overview of the GC-TOFMS discussed in this work. The instrument can be divided into three basic components (i) stream selection and sample preconcentration, (ii) gas chromatograph and (iii) mass spectrometer. Explanations are given in Sects. 2.1 to 2.3. Section 2.4 gives information on instrument control and data processing.

\subsection{Stream selection and sample preconcentration unit}

The setup described in this work allows for the attachment of five different air samples, a calibration gas and a blank gas. Gas stream selection is realized by solenoid valves (Fluid Automation Systems, Switzerland) that allow for sample pressures up to 5 bars absolute; i.e. a pressure reducer has to be used for high-pressure flasks. All tubing $\left(1 / 8^{\prime \prime}\right.$ stainless steel with Swagelok compression fittings, about $500 \mathrm{~mm}$ length) is heated to $>100^{\circ} \mathrm{C}$ to reduce accumulation of water and other sample components on tubing walls. All samples with tropospheric water content were dried prior to preconcentration using magnesium perchlorate which was heated to $80^{\circ} \mathrm{C}$.

The very low mixing ratio range of the targeted analytes in the parts per trillion (ppt) to parts per quadrillion (ppq) mole fraction constitutes the requirement for a preconcentration before analysis with GC-MS. The usage of adsorptive material for that purpose is a widespread procedure in instrumental analytics. Cooling the adsorption material shifts the steady state of the adsorption-desorption process towards adsorption and is referred to as "cryotrapping" or "cryofocusing". The combination of cryofocusingthermodesorption, i.e. rapidly heating the formerly cooled material for sample preconcentration and injection into an analytical instrument, has been quite common for nearly 20 years; see e.g. Simmonds et al. (1995), Kerwin et al. (1996) or Bassford et al. (1998) for the field of application related to this work.

A Sunpower CryoTel CT free-piston Stirling cooler (FPSC; Ametek Inc., USA) is used for cooling. On top of the cooler's cold tip, an anodized aluminium coldhead is placed which contains the sample loop, a $1 / 16^{\prime \prime}$ outer diameter and $1 \mathrm{~mm}$ inner diameter stainless steel tube. It is filled with HayeSep ${ }^{\circledR} \mathrm{D}$ adsorption material (Vici Valco Inc., USA) over a distance of about $100 \mathrm{~mm}$ with a mesh size of $80 / 100$ and a mass of about $20 \mathrm{mg}$ adsorption material.

The adsorption temperature is set to about $-80^{\circ} \mathrm{C}$ to quantitatively trap the lowest-boiling substance separated by the GC column from $\mathrm{CO}_{2}$ (HFC-23, $\mathrm{CHF}_{3}$, boiling point: $-82.1{ }^{\circ} \mathrm{C}$ ). For all measurements, a constant sample preconcentration flow rate of $100 \mathrm{~mL} \mathrm{~min}^{-1}$ is set by a mass flow controller (MFC; EL-FLOW F-201CM, Bronkhorst, the Netherlands) mounted directly downstream of the sample loop. The MFC can also be used for sample volume determination $(\Delta V)$. All components of the sample air which are not trapped on the adsorption material are collected in a 2 L stainless steel flask ("reference volume") equipped with a pressure sensor (Baratron 626, 0-1000 mbar, accuracy including non-linearity $0.25 \%$ of reading, MKS Instruments, Germany) for sample volume determination $(\Delta p)$. Tubing 
and reference volume are evacuated with a Vacuubrand MD-1 vario-SP membrane pump (Vacuubrand $\mathrm{GmbH} \&$ Co. KG, Germany) before each preconcentration step. For desorption, the sample loop is heated to about $220^{\circ} \mathrm{C}$ and flushed with carrier gas for $3 \mathrm{~min}$ to transport formerly trapped analytes onto the GC column. A similar sample preconcentration setup was described by Sala et al. (2014) and Hoker et al. (2015).

\subsection{Gas chromatograph}

An Agilent Technologies 7890B gas chromatograph is used to separate analytes before detection. A $0.32 \mathrm{~mm}$ ID Gas Pro PLOT column of $30 \mathrm{~m}$ length is used for chromatographic separation with purified helium 6.0 as carrier gas (Praxair Technologies Inc., German supplier. Purification System: Vici Valco HP2). The column is divided into a backwards flushable $7.5 \mathrm{~m}$ precolumn and a $22.5 \mathrm{~m}$ main column. Column head pressure was adjusted so that at maximum flow (lowest column temperature), the pressure inside the ionization chamber of the TOFMS is suitable $\left(<5 \times 10^{-5}\right.$ mbar $)$ and that on the other hand chromatographic peaks are kept sharp at minimum flow (highest column temperature). The head pressure of the carrier gas flow in line with the MS is kept constant at all times.

The gas chromatographic runtime is $16 \mathrm{~min}$, with an additional $3 \mathrm{~min}$ cooldown before the next run, which results in a total of $19 \mathrm{~min}$ per measurement. The initial oven temperature is $45^{\circ} \mathrm{C}$, which is held for $2.3 \mathrm{~min}$ and ramped linearly afterwards with $25^{\circ} \mathrm{C} \mathrm{min}^{-1}$ to $200^{\circ} \mathrm{C}$ and held until $16 \mathrm{~min}$. The precolumn is set to backflush position after the analyte with highest retention time $t_{\mathrm{R}}$ has reached the main column after $11 \mathrm{~min}$ to keep the gas chromatographic system free of contaminations with higher boiling compounds. The main column is connected to the MS with a $0.1 \mathrm{~mm}$ ID fused silica transfer line (length: about $350 \mathrm{~mm}$ ) inside the GC oven. The capillary feedthrough into the ionizer of the MS is kept at $210^{\circ} \mathrm{C}$ at all times.

Gas flow switching (backflush, injection, etc.) is implemented with two Valco 1/16" 6-port/2-position valves (Vici Valco Inc., USA) which are kept at $180^{\circ} \mathrm{C}$ outside the GC oven. Valco stainless steel $1 / 16^{\prime \prime}$ connectors with Valcon $\mathrm{T}$ ferrules are used for fused silica tubing (Vici Valco Inc., USA). Carrier gas flow, as determined by the Agilent Technologies flow calculator, is $4.0 \mathrm{~mL} \mathrm{~min}^{-1}$ at the beginning and $2.3 \mathrm{~mL} \mathrm{~min}^{-1}$ at the end of the run. However, actual flow rates should lie slightly lower, as the calculation only includes column and transfer line to the MS but no additional restrictions in the flow path like e.g. two Valco 2-position valves, the sample loop and column connectors.

Within the chromatographic runtime of $16 \mathrm{~min}$, a total of 68 substances were detected and identified (most of them halocarbons) in different air samples. The substance with the shortest retention time is $\mathrm{HFC}-23\left(\mathrm{CHF}_{3}, t_{\mathrm{R}}=3 \mathrm{~min}\right)$; the latest detectable substance is $\mathrm{CH}_{2} \mathrm{I}_{2}$ at $t_{\mathrm{R}}=15 \mathrm{~min}$.

\subsection{Time-of-flight mass spectrometer}

The mass spectrometer used in this work is a Tofwerk EI-TOF (model EI-003, Tofwerk AG, Switzerland) - an orthogonal extraction, single reflectron TOFMS with an electron ionization (EI) ion source, a quadrupole high-pass filter and a Photonis multichannel plate (MCP) electron multiplier (Photonis, USA). The PCIe data acquisition card records $1.6 \mathrm{GS} \mathrm{s}^{-1}$ with a $14 \mathrm{bit} \mathrm{s}^{-1} \mathrm{ADC}$ (analog-to-digital converter) using an on-board averaging firmware. Ions are extracted orthogonally with a rate of $22 \mathrm{kHz}$ into the flight chamber; about 5500 resulting waveforms are averaged to form one mass spectrum that is transferred to the PC and saved to the hard disk. Extraction frequency and number of averaged waveforms give a full spectra rate of $4 \mathrm{~Hz}$. A mass range of up to $600 \mathrm{Th}$ (Thomson; $1 \mathrm{Th}=1 u / e ; u$ : unified atomic mass unit, $e$ : atomic charge unit) is recorded, which corresponds to a maximum flight time of about $40 \mu \mathrm{s}$ at the given dimensions of the flight tube, acceleration voltage, etc.

The choice of spectra rate is a compromise between chromatographic signal integration demands and minimum noise levels. For the described gaschromatographic setup, chromatographic peaks typically have a minimum width of about $4 \mathrm{~s}$ ( $\pm 2 \sigma$ assuming Gaussian peak shape). As TOFMS in contrast to the quadrupole MS is not a scanning technique, the intensity of the chromatographic peak is sampled by the extraction rate $(22 \mathrm{kHz}$ in this case) and is therefore not subject to spectral skew - i.e. a relative change of ion signal intensity during the time it takes to scan the mass spectrum. A spectra rate of $4 \mathrm{~Hz}$ giving roughly 15 data points per chromatographic peak was chosen for comparability with our other GC-MS systems (see e.g. Hoker et al., 2015; Sala et al., 2014). For the TOFMS, a lower spectra rate should be possible due to the lack of spectral skew. However, the identification of the lowest possible and of the optimal spectra rate is beyond the scope of this work.

The current data acquisition hardware of the TOFMS theoretically allows for spectra rates of up to $1 \mathrm{kHz}(\mathrm{PCIe} \times 4$ port). However, as the extraction rate is constant $(22 \mathrm{kHz}$ in this case) and determined by the flight time of the heaviest ion produced in the ion source, a higher extraction rate causes fewer individual waveforms to be averaged which in consequence increases the noise level, assuming a relative error of mean of the counting events given as $1 / \sqrt{n}$, with $n$ being the number of waveforms in a spectrum.

The ionizer temperature was kept at $240^{\circ} \mathrm{C}$. Ionization energy was set to $70 \mathrm{eV}$ with an emission current of $0.5 \mathrm{~mA}$. Pressure inside the ionization chamber varied between $2.4 \times 10^{-5}$ and $4.2 \times 10^{-5} \mathrm{mbar}$, and pressure inside the flight chamber varied from $5.2 \times 10^{-7}$ to $8.4 \times 10^{-7} \mathrm{mbar}$ - both depending on GC runtime and column outflow. The quadrupole high-pass filter was set to attenuate $\mathrm{N}_{2}^{+}$and $\mathrm{O}_{2}^{+}$ 
signals and completely exclude ions lighter than $15 \mathrm{Th}$. This filter setting was kept constant during all chromatographic runs.

The MS is equipped with a calibrant pulser valve (Tofwerk AG, Switzerland) which can be programmed to release a few nanograms of a calibration substance (perfluoroperhydrophenanthrene, $\mathrm{C}_{14} \mathrm{~F}_{24}$, CAS 306-91-2) into the ionization chamber. To ensure mass axis stability, calibrant pulses were triggered at the beginning of each chromatogram, prior to the elution of any compound. By this procedure, the mass axis can be recalibrated in each chromatogram as part of data processing.

\subsection{Automation and data processing}

The analytical system can run a fully automated sequence of measurements. The automation is based on a LabVIEW cRIO system (National Instruments Inc., USA) which controls the system state (preconcentration, desorption, etc.) and can start GC and MS to record the chromatogram.

The analysis of high-resolution mass spectrometric data is performed in the IDL programming environment (Exelis Inc., USA) using asymmetric Lorentzian fits on mass peaks to determine peak width for mass resolving power and peak centre for mass accuracy.

Intensities of specific masses in each mass spectrum recorded during the chromatographic run are calculated by summing specified intervals of the mass axis. Both nominal and accurate mass intensities are derived from the same raw data. For nominal mass intensities, an interval of $\pm 0.3 \mathrm{Th}$ around the integer mass is used. For accurate mass intensities, an interval of $\pm 0.0250 \mathrm{Th}$ around the calculated exact mass is used unless noted otherwise.

Determination of noise levels and integration of chromatographic signals is done in IDL with a customwritten widget-based software named IAU_Chrom. Previous versions of this software were used by Sala et al. (2014) and Hoker et al. (2015). IAU_Chrom was extended to include import and processing tools as well as viewing functionality for the HDF5 file format of the Tofwerk MS data. Chromatographic noise levels are calculated as the 3 -fold standard deviation of the residuals between data points and a second-degree polynomial fit through these data points. This calculation is performed routinely for all quantifier masses on baseline sections with a typical length of $25 \mathrm{~s}$ which includes 100 data points in the calculation. Chromatographic peaks are integrated with a custom routine using the IDL "gaussfit" function. Signal heights used in signal-to-noise ratio calculation are also taken from this Gaussian fit.

Mixing ratios in the measured samples are determined by a relative calibration scheme, i.e. substance signals in sample chromatograms are referenced against respective signals in calibration gas chromatograms obtained from a high-pressure flask of ambient air with known mixing ratios.
A linear proportionality of injected amount and detector response is assumed. In a series of measurements, each sample measurement (or block of repeated measurements of the same sample) is bracketed by calibration gas measurements.

\section{Characterization}

Four aspects of the instrument are described in this section to give the reader an impression of the system's capabilities: mass accuracy and mass resolving power (Sect. 3.1), sensitivity and limits of detection (Sect. 3.2), measurement precision and reproducibility (Sect. 3.3) and non-linearity (Sect. 3.4). All results are based on GC-TOFMS data with recalibrated mass axis using signals from the calibrant pulser described in Sect. 2.3.

\subsection{Mass accuracy and resolving power}

Mass accuracy as used here refers to mass measurement accuracy, i.e. the accuracy of a measured mass-to-charge ratio $m_{\text {meas }} / Q$ compared to the corresponding calculated mass-to-charge ratio $m_{\text {calc }} / Q$. The relative mass error $E_{\mathrm{mac}}$ is calculated as $E_{\mathrm{mac}}=\frac{m_{\mathrm{meas}}-m_{\text {calc }}}{m_{\text {calc }}}$; multiplication by $10^{6}$ gives $E_{\mathrm{mac}}$ in ppm, which is the quantity that is referred to by mass accuracy. The term mass or ion mass is used synonymously to $m / Q$ with $Q=1$. The term mass resolving power is used according to the full width at half maximum (FWHM) definition of IUPAC (2014) as

$R=\frac{m}{\Delta m}=\frac{m_{\text {meas }}}{\operatorname{FWHM}\left(m_{\text {meas }}\right)}$.

Mass accuracy and resolving power are both core parameters of the MS. They are the basic determinants (in addition to sensitivity, see Sect. 3.2) of data quality with respect to measurement precision from a chromatographic point of view and the benefits from having accurate mass information for chemical identification. From an application point of view, mass resolving power determines whether neighbouring signals from ions of different masses can be separated and mass accuracy describes the uncertainty of the measured mass. Insufficient mass accuracy cannot be compensated by high mass resolving power and vice versa. In fact, low mass accuracy can render a high mass resolving power "unexploitable" to some extent as it represents the uncertainty of a found accurate mass.

Data from five different measurement series were analysed to determine what the achievable mass axis calibration quality is (minimum $E_{\mathrm{mac}}$ ) and how $E_{\mathrm{mac}}$ varies over time - i.e. during one measurement series and between different measurement series. Different configurations of the TOFMS giving different average mass resolving powers were tested to determine how mass accuracy, mass resolving power and signal intensity are correlated. 


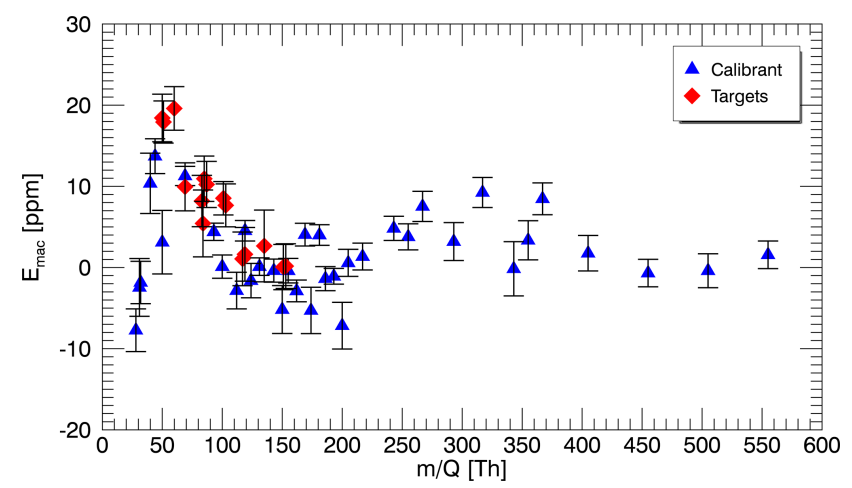

Figure 1. Mass accuracy $\left(E_{\mathrm{mac}}\right)$ in ppm over the whole mass range as determined for calibrant masses and masses of target substances during a measurement series. Error bars: 1-fold standard deviation from 44 individual measurements. Mean mass resolving power used in this measurement series: $R=3500$.

\subsubsection{Mass accuracy}

Experimental values for the mass accuracy of calibrant masses (28-555 Th) were found to be $E_{\text {mac }}=(4 \pm 0.3) \mathrm{ppm}$ as the arithmetic mean \pm 1 -fold standard deviation derived from five measurement series (186 measurements in total, based on absolute values of $E_{\text {mac }}$ ). Target substance masses (51-174 Th) within those measurement series showed a mean $E_{\mathrm{mac}}$ of ( $\left.8 \pm 0.8\right) \mathrm{ppm}$. Exemplary results for individual masses are shown in Fig. 1.

The variation of mass accuracies over the mass range is quite large relative to the mean value but generally not worse than $20 \mathrm{ppm}$, which is the manufacturer specification given as an absolute mass error of $\pm 0.002 \mathrm{Th}$ at $100 \mathrm{Th}$. This specification can be considered as a worst-case estimate, especially when signals are very small. The underlying mass axis calibration model was chosen from a selection readily available from the manufacturer to yield best results over the whole mass range. The observed systematic dependency of $E_{m}$ on $m / Q$ (Fig. 1) is likely an artifact of the chosen model; different models might be better suited for individual sections of the mass axis.

For the target masses from analytes, only a slightly elevated $E_{\text {mac }}$ was found compared to mass accuracies of calibrant masses used for mass axis calibration curve fitting. Mass accuracy also did not change significantly over the chromatographic runtime. Furthermore, mass accuracy was found to be stable over time, i.e. no significant trend over one measurement series or on average over different measurement series within a time span of multiple months as long as the same MS tuning was used. However, changes of $\sim 100 \mathrm{ppm}$ were observed during the first 1 to 2 hours of continuous measurement series (3-4 runs), probably caused by instrument warm-up and material elongation. This effect was compensated by the routinely executed recalibration of

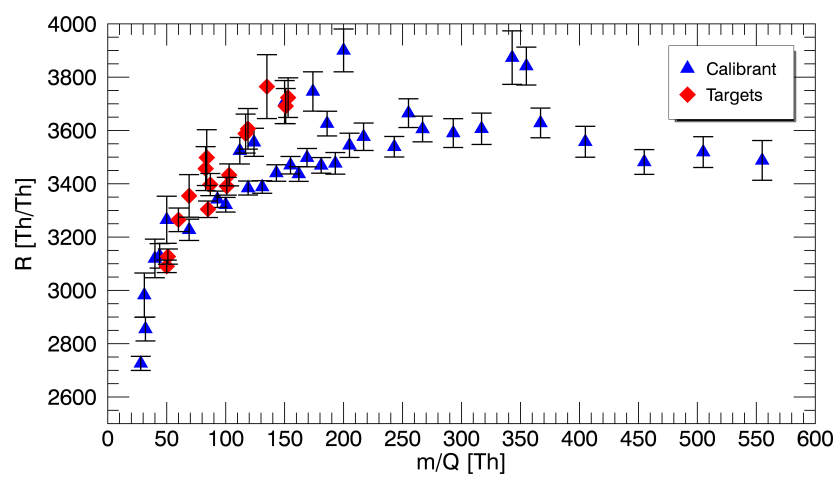

Figure 2. Mass resolving power over the whole mass range as determined for all mass axis calibration masses found in calibrant pulses during a measurement series as well as 15 target masses from analyte molecules. Error bars: 1-fold standard deviation of each mass over 44 individual measurements.

the mass axis in each chromatogram, thereby achieving the mass accuracies discussed above.

\subsubsection{Mass resolving power}

In TOFMS, mass resolving power is anti-proportional to sensitivity to a certain extent. Assuming an optimal ion beam focusing, higher sensitivity would require more ions of equal mass to reach the detector - which in turn would cause a higher arrival time distribution per mass (Guilhaus, 1995). To optimize sensitivity at the given spectra rate and sample volume, a configuration giving an average of $R=3500$ over the whole mass range was chosen. For further discussion of the effect of changes in mass resolving power on sensitivity, see Sect. 3.2.

Mass resolving power in general showed a stable behaviour over time, i.e. no significant trend during a measurement series or over multiple measurement series conducted with the same settings. Figure 2 shows the distribution of mass resolution along the mass axis. Resolving power for lighter ions is reduced compared to the average resolving power. This effect is known in TOFMS (e.g. Coles and Guilhaus, 1994) and caused mainly by the limited detection system bandwidth which determines single ion signal width. If a higher overall mass resolving power is enforced by instrument tuning (i.e. creating a narrower ion arrival time distribution), this limitation becomes clearly visible for lighter ions while heavier ions might not yet be affected. From an application point of view, this aspect has to be considered when very light ions (mass $<30 \mathrm{Th}$ ) are the focus of the analysis.

Based on an analysis of the mass axis calibration masses in routine measurement data (default resolving power setting $R=3500$ ), a slight negative correlation of mass resolving power and ion signal height was found with a Spearman rank correlation coefficient of $\rho=-0.4(p<0.05)$ in mean over the five analysed measurement series. The correlation 
Table 1. Experimentally determined fragmentation and measured ion masses of fragments from HFC-1234yf $\left(\mathrm{CH}_{2} \mathrm{CFCF}_{3}\right)$ in an air sample from a parking lot. Approximate HFC-1234yf mixing ratio in this sample: 3-4 ppt. For identification, the maximum intensity spectrum was chosen within the chromatographic peak.

\begin{tabular}{lrrrr}
\hline Fragment & $\mathrm{CF}_{3}^{+}$ & $\mathrm{C}_{2} \mathrm{H}_{2} \mathrm{~F}_{2}^{+}$ & $\mathrm{C}_{3} \mathrm{H}_{2} \mathrm{~F}_{4}^{+}$ & $\mathrm{C}_{3} \mathrm{H}_{2} \mathrm{~F}_{3}^{+}$ \\
\hline$m_{\text {calc }} / Q[\mathrm{Th}]$ & 68.9947 & 64.0119 & 114.0087 & 95.0103 \\
$m_{\text {meas }} / Q[\mathrm{Th}]$ & 68.9958 & 64.0116 & 114.0091 & 95.0126 \\
$E_{\text {mac }}[\mathrm{ppm}]$ & +16 & -5 & +3 & +24 \\
$\begin{array}{l}\text { Experimental } \\
\text { relative abundance }\end{array}$ & 1 & 0.78 & 0.64 & 0.40 \\
\hline
\end{tabular}

between mass accuracy and ion signal height was found to be $\rho=+0.2$ but with very high $p$ values $>0.1$ and therefore of low significance. The correlation was more pronounced with $\rho=-0.8$ (resolving power) and $\rho=+0.8$ (mass accuracy) for the target ions from analyte molecules, both correlations with $p$ values $<0.01$.

The correlation of mass resolving power and intensity implies that a very small signal has an above-average mass resolution as smaller signals get effectively narrower due to decreased ion velocity disturbance by other ions of equal mass. This effect is clearly visible for the target substance ions and also selected calibrant masses displayed in Fig. 2; every mass with an elevated mass resolution compared to an interpolated mass-to- $R$ curve in Fig. 2 was found to have below-average signal intensity (calibrant as well as targets). When becoming even smaller, signals are on the other hand afflicted with below-average mass accuracy as counting statistics quality decreases.

\subsubsection{Exemplary identification of HFC-1234yf}

Substance HFC-1234yf $\left(\mathrm{CH}_{2} \mathrm{CFCF}_{3}\right.$, CAS 754-12-1) was introduced as a replacement for HFC-134a $\left(\mathrm{CH}_{2} \mathrm{FCF}_{3}\right)$ in mobile air conditioning systems in 2011 and can already be detected at remote measurement sites as published by Vollmer et al. (2015). The identification of emerging substances like the one used as an example here is often difficult due to an unknown fragmentation. However, the $\mathrm{CH}_{2} \mathrm{CFCF}_{3}$ molecule should form $\mathrm{CF}_{3}^{+}$(69 Th), $\mathrm{CH}_{2} \mathrm{CF}^{+}$ (45 Th), $\mathrm{CH}_{2} \mathrm{CF}_{2}^{+}$(64 Th), $\mathrm{CH}_{2} \mathrm{CFCF}_{3}^{+}$(114 Th) and related ions. Likelihood of identification can then be significantly increased by using accurate mass information. Table 1 shows experimentally determined fragmentation and measured masses of the four most abundant fragments observed in an air sample with an elevated concentration of HFC-1234yf; the chromatographic peak of HFC-1234yf is shown in Fig. 3. Thanks to the all-time full mass range data acquisition of the TOFMS, no dedicated mass filter settings are necessary for identification as would be the case with a quadrupole MS.
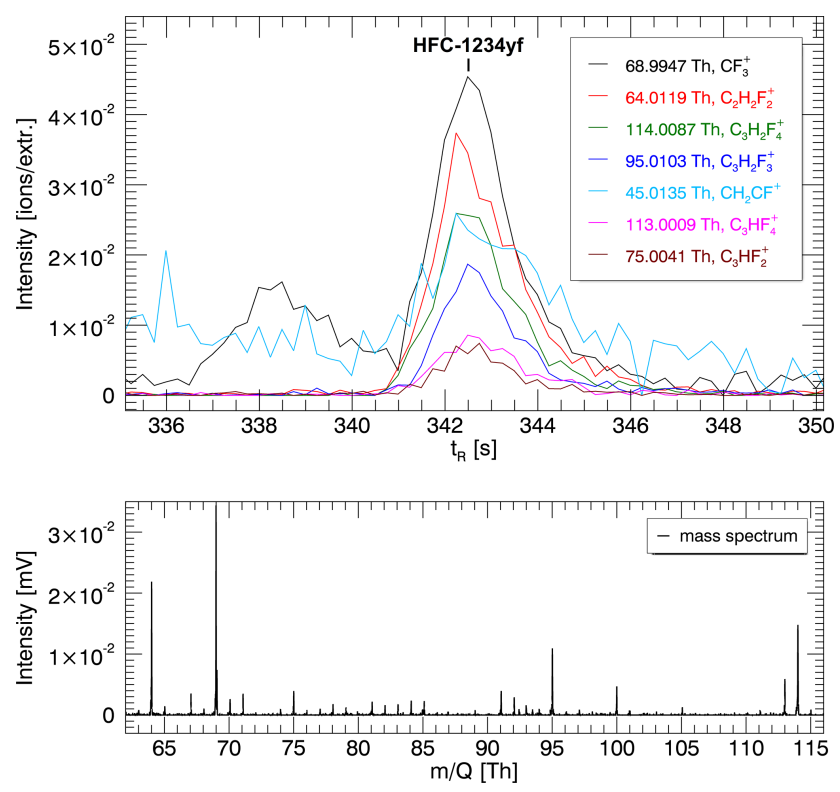

Figure 3. Upper graph: chromatographic signal of HFC-1234yf $\left(\mathrm{CH}_{2} \mathrm{CFCF}_{3}\right)$ at a retention time $\left(t_{\mathrm{R}}\right)$ of $343 \mathrm{~s}$ observed in an air sample from a parking lot. Lower graph: mass spectrum excerpt at the chromatographic peak apex. $Y$ axis unit conversion, lower to upper graph: divide by the number of extractions per spectrum and the signal intensity of a single ion (determined separately).

\subsection{Sensitivity and limits of detection}

To characterize the analytical system in respect to its sensitivity, the lowest detectable amount of a substance (limit of detection, LOD) is the quantity of interest. Due to the general applicability to all signals caused by substances with known mixing ratios in the sample, a signal-to-noise ratio ( $S / N$; signal represented by the signal height) of $2: 1$ was chosen as detection limit in accordance with IUPAC (1998).

As the instrument discussed here offers the possibility to increase sensitivity by trading off mass resolving power (see also Sect. 3.1), changes in sensitivity were analysed relative to different mass resolving power settings of the MS. Furthermore, the detector is not independent of the chromatographic system; its effects on noise levels are therefore discussed based on the analysis of different baseline sections from a sample measurement series. To answer the question of where the actual limits of detection lie, a practical example is given for the substance Halon-1202 $\left(\mathrm{CF}_{2} \mathrm{Br}_{2}\right)$ which was detected at $S / N \approx 2$. Additional LOD for different substances were derived from measurements of different ambient air samples to include possible sample matrix effects on LOD. A description of the applied noise level and signal height determination was given in Sect. 2.4. 
Table 2. Comparison of different resolving power settings with regard to changes in sensitivity. Values based on 10 measurements per setting and 37 calibration masses for resolution calculation (avg. $R, \Delta R$ ). Changes in $S / N(\Delta S / N)$ determined as the mean relative change in $S / N$ for 39 substances. From the total of 68 identified substances, a variable fraction could be integrated depending on the resolving power setting as shown in the last column ( $n$ subst. integrated). All values were determined with accurate mass intensities.

\begin{tabular}{lrrr}
\hline avg. $R$ & $\Delta R$ & $\Delta S / N$ & $n$ subst. integrated \\
\hline 2577 & $-27 \%$ & $+38 \%$ & $59(+9 \%)$ \\
3545 & $100 \%$ & $100 \%$ & 54 \\
4477 & $+26 \%$ & $-64 \%$ & $39(-28 \%)$ \\
\hline
\end{tabular}

\subsubsection{Sensitivity and its interdependence on mass resolving power}

As pointed out before, an increase in sensitivity of the TOFMS goes along with reduced mass resolving power (see Sect. 3.1). The task for the user is to choose a resolving power setting which gives optimum sensitivity and data density for the desired application and spectra rate.

Table 2 shows a comparison of three different mass resolving power settings and the resulting changes in sensitivity, represented by a change in $S / N$ relative to the default setting. While mass resolving power changed by approximately $\pm 25 \%$ relative to the commonly used setting $R=3500$, the changes in $S / N$ are more pronounced with +38 and $-64 \%$. This implies that the anti-correlation between resolving power and sensitivity is not linear and has an optimum that depends on the user's requirements. The final column of Table 2 gives a more practical view on the experiment: the number of integrable substance signals substantially decreases with increasing mass resolving power. However, the change in number of integrable substances does not totally reflect the change in $S / N$. This can be related to the integration method and/or individual properties of the chosen substances.

\subsubsection{Dependence on chromatographic effects}

A key parameter in the discussion of sensitivity is the noise level. A special property of a chromatographic system is that noise levels can change over the chromatographic runtime with changing column temperature and pressure due to increased mobility of high-boiling compounds, column bleeding, etc. In most cases, column temperature and noise level are positively correlated. Furthermore, the correlation strength also depends on ion mass.

For the GC-MS system discussed here, Table 3 shows a comparison of three different ion masses typically formed by halocarbons and their change of noise level depending on the baseline section where noise is calculated. It has

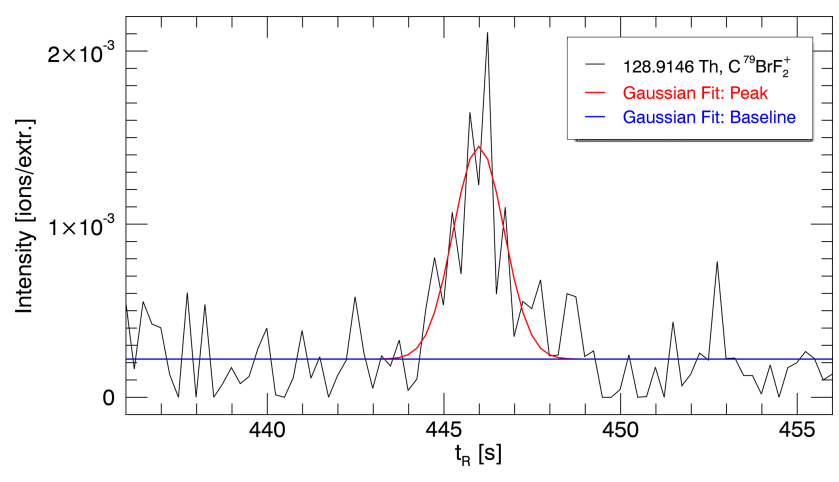

Figure 4. Chromatographic signal of Halon-1202 $\left(\mathrm{CF}_{2} \mathrm{Br}_{2}\right)$ on mass $128.9146 \mathrm{Th}\left(\mathrm{C}^{79} \mathrm{BrF}_{2}^{+}\right.$fragment) at a retention time $\left(t_{\mathrm{R}}\right)$ of $446 \mathrm{~s}$. Sample: H-218 flask AGAGE calibration gas, $490 \mathrm{~mL}$ preconcentration volume.

to be pointed out that noise levels change by factors of $\sim 3$ depending on the position in the chromatogram. Limits of detection based on $S / N$ are therefore dependent on the retention time and qualifier/quantifier ion of the substance of interest. The detection limits of substances with ion masses displayed in Table 3 seem to be limited by the chromatographic system (and not the MS) towards higher retention times as noise levels tend to increase over the chromatographic runtime.

To illustrate the benefit of the use of accurate mass information on noise levels, Table 4 shows a comparison of the noise levels for $m / Q 69 \mathrm{Th}$, comparing intensities derived from the nominal mass interval $(69 \pm 0.3 \mathrm{Th})$ to intensities derived from narrow mass interval around the calculated mass of the $\mathrm{CF}_{3}^{+}$ion $(68.9947 \pm 0.025 \mathrm{Th})$. This ion mass is known to be quite noisy relative to other ion masses, especially later in the chromatogram as demonstrated in Table 3 (column 3 vs. column 2).

Two things can be observed: first, noise levels are significantly reduced by ca. $70 \%$ in all samples when using the accurate mass intensities instead of the nominal mass intensities. Second, the relative comparison of the noisiest sample (S_01) shows that the elevation in noise level, compared to the other samples, is strongly reduced when the accurate mass is used (70\% elevation on nominal mass intensities vs. $12 \%$ elevation on accurate mass intensities). The analytical system gains independence from sample matrix effects by the usage of accurate mass intensities.

\subsubsection{Detection limits derived from quantified substances}

To demonstrate detection limits from a practical point of view, Fig. 4 shows the integrated signal of Halon-1202 $\left(\mathrm{CBr}_{2} \mathrm{~F}_{2}\right)$ which was detected and integrated at a signal-tonoise ratio of $\approx 2$.

A mixing ratio of $(0.035 \pm 0.006) \mathrm{ppt}$ was determined for the sample shown here (calibration scale of Halon-1202: 
Table 3. Intra-sample comparison of noise levels on three typical halocarbon ion masses (nominal mass intensities). For each ion mass, two baseline sections were chosen for noise calculation, at the beginning and towards the end of the chromatogram. Noise levels and according $1 \sigma$ standard deviations were determined over 40 chromatograms measuring the same reference gas and constant sample volume of $0.66 \mathrm{~L}$. The $\Delta$ Noise row shows noise on late baseline section divided by noise on early baseline section.

\begin{tabular}{ll|l|l|l|l|l}
\hline Mass: & \multicolumn{2}{c|}{ 69 Th nominal } & \multicolumn{2}{c|}{ 85 Th nominal } & \multicolumn{2}{c}{ 101 Th nominal } \\
\hline Baseline section [s] & $200-225$ & $930-950$ & $200-225$ & $930-950$ & $200-225$ & $800-825$ \\
(Noise $\pm 1 \sigma) \times 10^{-3}$ & $4.5 \pm 0.50$ & $17 \pm 2.0$ & $1.5 \pm 0.13$ & $4.1 \pm 0.35$ & $0.96 \pm 0.076$ & $3.2 \pm 0.21$ \\
$\Delta$ Noise (late/early) & 3.7 & & 2.7 & & 3.3 & \\
\hline
\end{tabular}

Table 4. Inter-sample comparison of noise levels on nominal mass $(69 \pm 0.3) \mathrm{Th}$ and accurate mass $68.9947 \pm 0.025 \mathrm{Th}\left(\mathrm{CF}_{3}^{+}\right)$for four different samples. Both signals were extracted from the same raw data as described in Sect. 2.4. Noise levels were calculated as means over five measurements per sample on a baseline section from 870 to $895 \mathrm{~s}$ chromatographic time. Errors given as the corresponding 1-fold standard deviations. All samples were measured in one measurement series with constant sample volume and the same MS settings.

\begin{tabular}{lllll}
\hline Sample & S_01 & S_02 & S_03 & S_04 \\
\hline Nominal 69 Th: $($ noise $\pm 1 \sigma) \times 10^{-3}$ & $32 \pm 0.7$ & $19 \pm 1.3$ & $19 \pm 1.7$ & $17 \pm 0.9$ \\
$\mathrm{CF}_{3}^{+}$, 68.9947 Th: $($noise $\pm 1 \sigma) \times 10^{-3}$ & $7.2 \pm 0.32$ & $6.4 \pm 0.20$ & $6.8 \pm 0.75$ & $6.3 \pm 0.32$ \\
Noise ratio, nominal/accurate & 4.4 & 3.0 & 2.8 & 2.7 \\
\hline
\end{tabular}

UEA-2009). For a $1 \mathrm{~L}$ air sample, the calculation gives a LOD of $(0.016 \pm 0.003) \mathrm{ppt}$, which equals $(0.138 \pm 0.024) \mathrm{pg}$ Halon-1202 per litre of air at standard temperature and pressure.

LOD were found in the sub-ppt and sub-pg range for all analysed substances and even go down to the low ppq or fg range for some species. Detection on accurate mass instead of detection on nominal mass yields LOD improvements by factors of 5 and more. Table 5 shows an excerpt from calculated LOD for six different substances roughly covering the mass and retention time range of the chromatogram.

LOD were calculated as arithmetic means of five different samples measured five times each during one measurement series as well as the calibration gas to include sample matrix effects on detection limits.

From Table 5 it can be observed that the compounds Halon-1301 $\left(\mathrm{CBrF}_{3}\right)$ and HCFC-22 $\left(\mathrm{CHClF}_{2}\right)$, both detected on fluorinated fragments, show less improvement in LOD on accurate mass compared to the other three compounds. An explanation could be that the noise on nominal mass 51 and $69 \mathrm{Th}$ is caused mainly by the $\mathrm{CHF}_{2}^{+}$and $\mathrm{CF}_{3}^{+}$fragments, especially for the corresponding relatively early baseline sections (see also Table 4). In comparison, the $\mathrm{CH}_{2}^{35} \mathrm{Cl}_{2}^{+}$ and $\mathrm{CH}_{2}^{79} \mathrm{Br}^{81} \mathrm{Br}^{+}$from dichloromethane $\left(\mathrm{CH}_{2} \mathrm{Cl}_{2}\right)$ and dibromomethane $\left(\mathrm{CH}_{2} \mathrm{Br}_{2}\right)$ show much more pronounced improvements as most of the noise is potentially not produced by those fragments.

In general, we cannot quantify how much sensitivity will be gained for which ion mass. A strong positive correlation was found between retention time and mass over the full substance range with $r=0.70\left(p<10^{-7}\right)$. It is therefore very difficult to disentangle, if there also is e.g. a significant correlation between gain in $S / N$ and mass (attributing the effect to the MS) or gain in $S / N$ and $t_{\mathrm{R}}$ (attributing the effect to the chromatographic system).

\subsection{Precision and reproducibility of quantification}

In order to quantify small trends of long-lived species like CFC-12, CFC-11 or CFC-113 (Carpenter et al., 2014) with only a few individual measurements, a high measurement precision is necessary. Additionally, high measurement precision is a prerequisite to analyse systematic effects and potential systematic errors like system non-linearities in measurement data.

Measurement precision as variability of the measured values around a mean value (random error) is analysed with so-called precision experiments consisting of up to 50 measurements of the same reference gas with constant sample volume. Within this series, a subset of measurements is treated as calibration points and another subset as samples. This gives blocks of repeated sample measurements between bracketing calibration points. Calibration is achieved by linear interpolation between calibration points and referencing the bracketed samples to the calibration, giving a relative response for every sample measurement. An ideal measurement should give a relative response of 1 ; i.e. the spread around 1 represents the measurement precision. Measurement precision of an individual measurement is then taken to be the mean standard deviation of all sample subsets of the series. To gain information about the reproducibility of the measurement precision derived from individual experiments, multiple precision experiments as well as routine sample measurement series were taken into consideration. A normal sample measurement is principally 
Table 5. Limits of detection for six different species with different retention times and fragment masses: values derived from the analysis of five different air samples calibrated against a secondary standard of the AGAGE network (flask H-218) as well as the calibration gas itself (mean LOD shown). Sample volume was extrapolated from approximately $490 \mathrm{~mL}$ to $1 \mathrm{~L}$. LOD were calculated based on an evaluation of the respective (1) nominal and (2) accurate mass intensities (see Sect. 2.4 for details). Errors were derived from mean errors of noise and height calculation for each sample. The ratio of nominal mass LOD to accurate mass LOD is shown in the last column.

\begin{tabular}{|c|c|c|c|c|c|c|c|c|}
\hline \multirow[b]{2}{*}{ Substance } & \multirow[b]{2}{*}{$\begin{array}{l}t_{\mathrm{R}} \\
{[\mathrm{s}]}\end{array}$} & \multirow[b]{2}{*}{ Fragment } & \multirow[b]{2}{*}{$\begin{array}{l}m_{\text {calc }} / Q \\
{[\mathrm{Th}]}\end{array}$} & \multicolumn{2}{|c|}{ (1) nominal } & \multicolumn{2}{|c|}{ (2) accurate } & \multirow[b]{2}{*}{ nom./acc. } \\
\hline & & & & $\begin{array}{l}\text { LOD } \\
{[\mathrm{ppt}]}\end{array}$ & $\begin{array}{l}\text { LOD } \\
{[\mathrm{pg}]}\end{array}$ & $\begin{array}{l}\text { LOD } \\
{[\mathrm{ppt}]}\end{array}$ & $\begin{array}{l}\text { LOD } \\
{[\mathrm{pg}]}\end{array}$ & \\
\hline Halon-1301 & 232 & $\mathrm{CF}_{3}^{+}$ & 68.9947 & $\begin{array}{l}0.107 \\
\pm 0.0076\end{array}$ & $\begin{array}{l}0.644 \\
\pm 0.0453\end{array}$ & $\begin{array}{l}0.105 \\
\pm 0.0071\end{array}$ & $\begin{array}{l}0.631 \\
\pm 0.0428\end{array}$ & 1.0 \\
\hline HCFC-22 & 313 & $\mathrm{CHF}_{2}^{+}$ & 51.0041 & $\begin{array}{l}0.079 \\
\pm 0.0040\end{array}$ & $\begin{array}{l}0.277 \\
\pm 0.0138\end{array}$ & $\begin{array}{l}0.066 \\
\pm 0.0043\end{array}$ & $\begin{array}{l}0.230 \\
\pm 0.0150\end{array}$ & 1.2 \\
\hline Halon-1211 & 379 & $\mathrm{CF}_{2}^{35} \mathrm{Cl}^{+}$ & 84.9651 & $\begin{array}{l}0.078 \\
\pm 0.0346\end{array}$ & $\begin{array}{l}0.517 \\
\pm 0.2306\end{array}$ & $\begin{array}{l}0.054 \\
\pm 0.0038\end{array}$ & $\begin{array}{l}0.357 \\
\pm 0.0253\end{array}$ & 1.4 \\
\hline Dichloromethane & 491 & $\mathrm{CH}_{2}^{35} \mathrm{Cl}_{2}^{+}$ & 83.9528 & $\begin{array}{l}0.123 \\
\pm 0.0039\end{array}$ & $\begin{array}{l}0.421 \\
\pm 0.0132\end{array}$ & $\begin{array}{l}0.022 \\
\pm 0.0018\end{array}$ & $\begin{array}{l}0.075 \\
\pm 0.0063\end{array}$ & 5.6 \\
\hline Halon-2402 & 516 & $\mathrm{C}_{2} \mathrm{~F}_{4}^{79} \mathrm{Br}^{+}$ & 178.9114 & $\begin{array}{l}0.008 \\
\pm 0.0003\end{array}$ & $\begin{array}{l}0.086 \\
\pm 0.0029\end{array}$ & $\begin{array}{l}0.003 \\
\pm 0.0003\end{array}$ & $\begin{array}{l}0.034 \\
\pm 0.0028\end{array}$ & 2.5 \\
\hline Dibromomethane & 606 & $\mathrm{CH}_{2}^{79} \mathrm{Br}^{81} \mathrm{Br}^{+}$ & 173.8497 & $\begin{array}{l}0.018 \\
\pm 0.0011\end{array}$ & $\begin{array}{l}0.128 \\
\pm 0.0078\end{array}$ & $\begin{array}{l}0.004 \\
\pm 0.0004\end{array}$ & $\begin{array}{l}0.030 \\
\pm 0.0027\end{array}$ & 4.3 \\
\hline
\end{tabular}

the same as a precision experiment with the exception that a real air sample instead of a reference gas is analysed in a sample block.

\subsubsection{Measurement precision}

Measurement precision in regard to analyte quantification for a single measurement was found to be better than $1 \%$ for about 15 out of 47 analysed substances and in good correlation with the signal-to-noise ratio of the respective substances. Best values were achieved for CFC-12 at exact ion mass $84.9651\left(\mathrm{CF}_{2}^{35} \mathrm{Cl}^{+}\right)$with $0.15 \%$ individual measurement precision and $0.08 \%$ error of mean for sample blocks of three subsequent measurements of the same sample (evaluation of accurate mass).

Figure 5 illustrates the precision range of the instrument for 47 analysed substances (mostly halocarbons, evaluation of nominal mass intensities) and their correlation with the signal-to-noise ratio. It can be observed that measurement precision exponentially improves with exponentially increasing signal-to-noise ratio with a good correlation coefficient of $r^{2}=0.86$. The quality of the correlation was underlined during routine measurements by the fact that outliers did indicate "problematic" substances like e.g. methyl iodide which was found in the system blank.

The lower end of precision ( $>10 \%$ ) is limited by signal quality - i.e. signals with a signal-to-noise ratio $<3$ constitute a problem for the integration routine used to determine signal area. At the high end of precision, a very large increase in $S / N$ seems to be necessary to achieve higher precision, i.e. approximately doubling the sample volume from 0.66 to $1.33 \mathrm{~L}$ to improve precision from 0.2 to $0.1 \%$. A precision

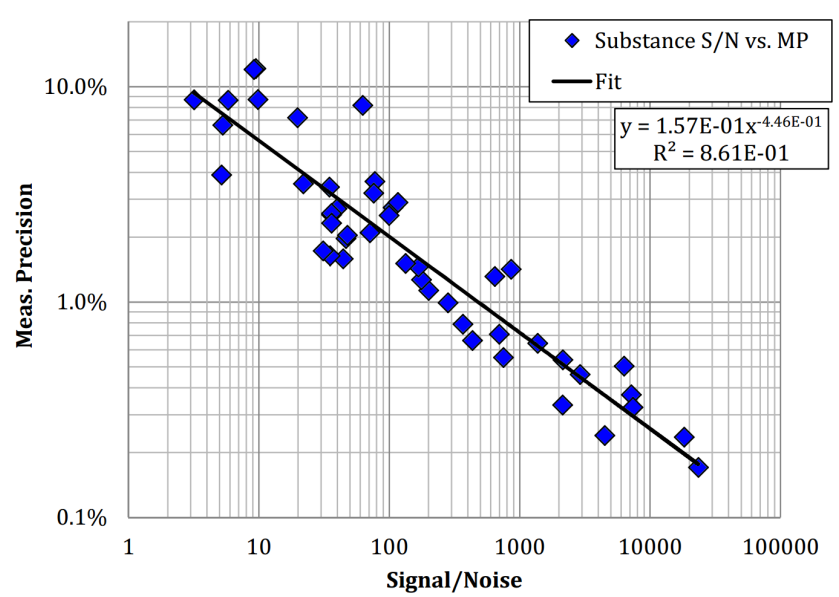

Figure 5. Correlation of measurement precision ( $y$ axis, MP) and signal-to-noise ratio ( $x$ axis) on a double-logarithmic plot. Data derived from repeated measurements of the same reference gas at constant sample volume of about $0.66 \mathrm{~L}$; evaluation based on nominal mass intensities.

experiment with a preconcentration volume of about $1.38 \mathrm{~L}$ showed that this theoretical extrapolation of the correlation is not valid. $S / N$ did increase but not linearly and measurement precision was even lower in mean although it was improved for some species, mostly in the lower $S / N$ regime $<100$. These findings imply that chromatographic effects play an important role and that there is an optimum sample volume if overall measurement precision should be maximized with a given chromatographic setup. 


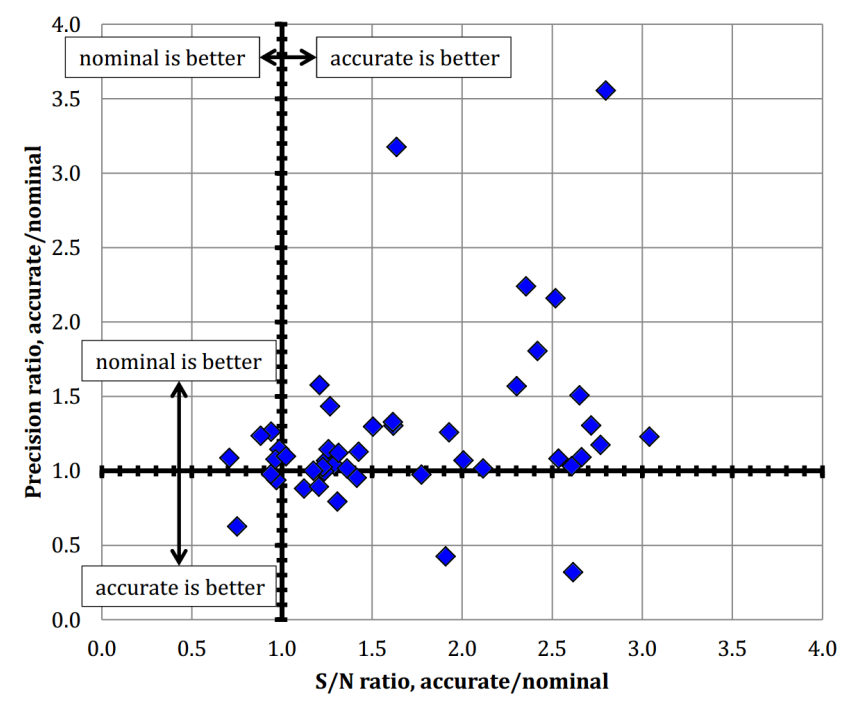

Figure 6. Corresponding ratios of signal-to-noise ( $x$ axis) and measurement precision ( $y$ axis) of values determined with accurate mass intensities relative to values determined with nominal mass intensities. Each diamond represents a substance which was evaluated on both nominal and accurate masses. Data based on repeated measurements of the same reference gas at constant sample volume of about $0.66 \mathrm{~L}$, see Fig. 5. While $S / N$ is improved for almost all substances using the accurate mass intensities, a slight decrease in measurement precision is observed compared to values derived with nominal mass intensities.

\subsubsection{Benefits from accurate mass information}

As the Tofwerk AG mass spectrometer allows the use of the information gained by a significantly higher than nominal mass resolving power, the question arises of how signal-tonoise ratios and measurement precision are influenced by the use of accurate mass information for further data processing.

Accurate masses comprise mass accuracy as an additional error source if fixed mass intervals are used to obtain them. Consequently, the correlation of measurement precision and signal-to-noise ratio is less pronounced $\left(r^{2}=0.75\right)$ for the same experiment shown in Fig. 5 and overall measurement precision is slightly decreased ( 10 out of 53 vs. 15 out of 47 better than $1 \%$ ), even if it is also increased for some species. Signal-to-noise ratios are increased in almost all cases using accurate masses. The changes in both quantities, measurement precision and signal-to-noise, relative to values determined for nominal masses are shown in Fig. 6.

While $S / N$ is mostly increased by factors up to 3 when comparing accurate mass to nominal mass evaluation, a coinciding decrease in measurement precision can be observed (upper right quadrant of Fig. 6). However, this is not strictly true for all analysed substances; some are improved in both quantities by using the accurate mass information instead of the nominal mass information (lower right quadrant of Fig. 6). A possible explanation is the
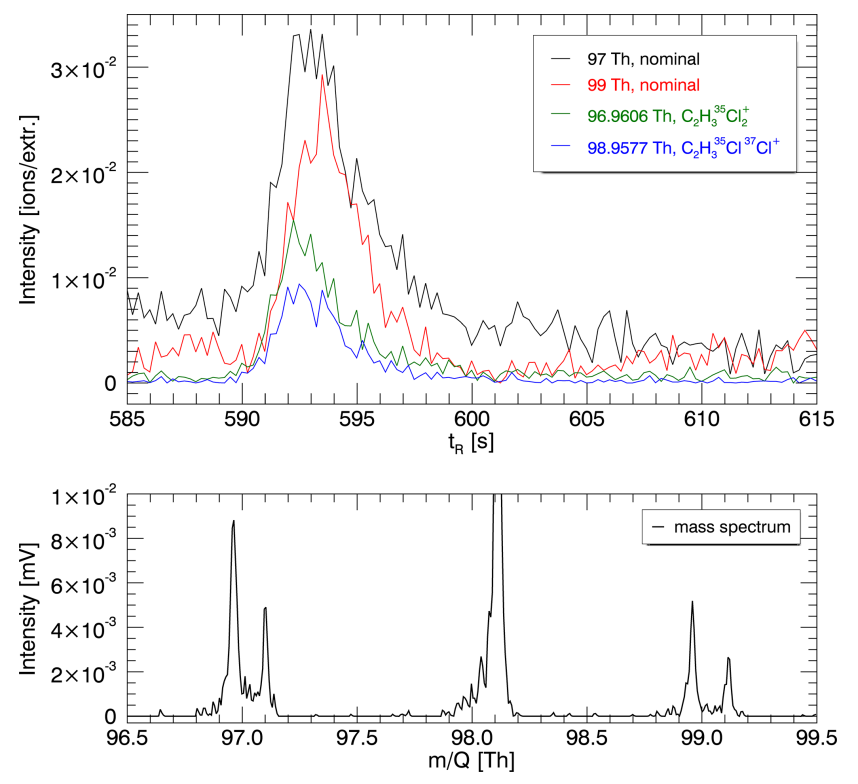

Figure 7. Upper graph: chromatographic signal of methyl chloroform $\left(\mathrm{CH}_{3} \mathrm{CCl}_{3}\right)$ on ion masses 97 and $99 \mathrm{Th}$, nominal mass intensities shown in black and red, accurate mass intensities shown in green and blue. Lower graph: mass spectrum excerpt at the chromatographic peak apex. A coeluting substance with matching retention time and nominal masses 97 and 99 Th leads to a systematic error in mixing ration determination if the nominal mass intensity is used for substance quantification. Unit conversions, $y$ axis of lower to upper graph: see Fig. 3.

interference from other ions with matching nominal mass caused by an unknown substance in the specific retention time window. This interference can be compensated by the use of accurate masses, if the accurate ion masses from known and unknown compound differ in that case. Only very few substances show better $S / N$ and better measurement precision on nominal masses (upper left quadrant of Fig. 6) and only one substance exhibits a better measurement precision on the accurate mass together with a decreased $S / N$ ratio (lower left quadrant of Fig. 6). The substance was identified to be methyl chloroform $\left(\mathrm{CH}_{3} \mathrm{CCl}_{3}\right)$.

This substance is an example of how the accuracy of substance quantification can be improved in some cases by using the accurate mass information as illustrated in Fig. 7. A narrow mass interval can compensate the coelution of a substance with matching nominal mass but deferring accurate mass. In such cases, the accurate mass from the GCTOFMS system is likely to give a mixing ratio much closer to the true value.

\subsubsection{Reproducibility and instrument stability}

To demonstrate measurement precision over a longer time period and varying conditions, Table 6 displays mean single measurement precision of 10 selected substances derived from five idealized precision experiments and four routine 
Table 6. Mean measurement precision and relative drift in calibration of 10 selected substances which were chosen according to a precision of generally better than $1 \%$. Data are based on five different precision experiments using different reference gases and sample volumes from 0.49 to $1.38 \mathrm{~L}$ as well as four routine measurement series including four to five samples per series. Precision values were calculated as the arithmetic mean of all sample blocks per measurement series. Drift calculated as minimum to maximum range of normalized chromatographic signal areas of calibration measurements within the routine measurement series (10-16 h total duration). Errors are displayed as the 1-fold standard deviation over all values used per substance. All measurements were conducted with a TOFMS configuration giving an $R$ of 3500 in mean.

\begin{tabular}{llll}
\hline Substance & $\begin{array}{l}\text { Measurement precision, } \\
\text { idealized experiments }\end{array}$ & $\begin{array}{l}\text { Measurement precision, } \\
\text { routine measurements }\end{array}$ & $\begin{array}{l}\text { Drift in calibration, } \\
\text { routine measurements }\end{array}$ \\
\hline CFC-12 & $(0.22 \pm 0.06) \%$ & $(0.30 \pm 0.09) \%$ & $(5.49 \pm 4.24) \%$ \\
Chloromethane & $(0.28 \pm 0.08) \%$ & $(0.45 \pm 0.20) \%$ & $(6.01 \pm 3.56) \%$ \\
CFC-11 & $(0.28 \pm 0.08) \%$ & $(0.29 \pm 0.04) \%$ & $(5.62 \pm 4.37) \%$ \\
HCFC-22 & $(0.30 \pm 0.06) \%$ & $(0.49 \pm 0.22) \%$ & $(5.23 \pm 3.82) \%$ \\
Carbonylsulfide & $(0.42 \pm 0.10) \%$ & $(0.39 \pm 0.17) \%$ & $(8.47 \pm 7.99) \%$ \\
Dichloromethane & $(0.52 \pm 0.10) \%$ & $(0.48 \pm 0.24) \%$ & $(8.07 \pm 3.35) \%$ \\
HFC-134a & $(0.54 \pm 0.23) \%$ & $(0.55 \pm 0.15) \%$ & $(6.05 \pm 5.15) \%$ \\
CFC-113 & $(0.55 \pm 0.08) \%$ & $(0.39 \pm 0.11) \%$ & $(6.48 \pm 3.99) \%$ \\
HCFC-142b & $(0.67 \pm 0.15) \%$ & $(0.83 \pm 0.06) \%$ & $(5.54 \pm 5.23) \%$ \\
Tetrachloromethane $\%$ & $(0.68 \pm 0.21) \%$ & $(0.65 \pm 0.09) \%$ & $(6.31 \pm 4.77) \%$ \\
\hline
\end{tabular}

measurement series. Only values derived from nominal mass evaluation are shown, as these serve as an internal reference to us and are directly comparable to our GC quadrupole MS instrument (e.g. Hoker et al., 2015).

The selection and order within Table 6 is based on best average measurement precision within the underlying precision experiments. Measurement precision in routine ambient air sample measurement series is subject to a greater variability as sample matrix, water content etc. also varies. This can be observed in column 3 of Table 6, where precision values derived from routine measurement series are shown. Precision values are slightly elevated compared to values derived from idealized experiments, as expected. However, all values are in good agreement considering the standard deviation of the estimated single measurement precision of the selected substances.

Column 4 of Table 6 shows maximum to minimum differences for normalized signal areas of calibration measurements for each substance to give information about instrument drift over routine measurement series, which typically took $10-16 \mathrm{~h}$ of continuous operation. The instrument was found to be less stable (10-20\% drift) if highly contaminated (e.g. by hydrocarbons) and/or very moist samples were measured or if measurements were conducted directly after start-up of the MS, e.g. after downtime due to ion source cleaning and filament replacement.

\subsection{Non-linearity}

As described in Sect. 2.4, a linear proportionality of mixing ratio in the sample and detector response is assumed for quantification. If mixing ratios in sample and calibration gas differ and the detector features significant non-linearities within the observed concentration range, measurement accuracy is decreased by the degree of the non-linearity. A correction of non-linearities as a post-processing step is only possible if non-linearities are systematic or very well understood. In any case, non-linearity correction adds an additional error source and is very time consuming and often complex as it can be different for every target substance.

To analyse non-linearity of the GC-TOFMS, volume variation experiments were conducted similar to the precision experiments described in Sect. 3.3 only that different volumes from the same high-pressure flask (reference gas) were preconcentrated and used as "samples". Variation volumes of $0.1-1.0 \mathrm{~L}$ from the reference gas were compared to $0.5 \mathrm{~L}$ calibration points (reference volume). For volume determination, the MFC installed in the system (see Sect. 2.1) was used. Volumes determined in parallel by the MFC and by the pressure sensor derived from $\Delta p$ were found to correlate linearly $\left(r^{2}>0.999998\right)$. All volume-corrected chromatographic signal areas $(A / V)$ were normalized $(n(A / V))$ by dividing them by the drift-corrected calibration $A / V$. The ratio of any sample $n(A / V)$ to the calibration $n(A / V)$ at that point within the measurement series, which was calculated by linear interpolation of the bracketing calibration $n(A / V)$, should give a relative response (rR) of 1 in case of a linear system. A deviation of up to the 3-fold measurement precision from a relative response of 1 was still considered to be linear behaviour. Substances with known memory or blank effects were excluded from the analysis.

Figure 8 shows exemplary results from the volume variation experiment described in the previous paragraph of this section. Two exemplary substances are shown: CFC-12 and HFC-134a (reference gas mixing ratios: 522 and $113 \mathrm{ppt})$. 

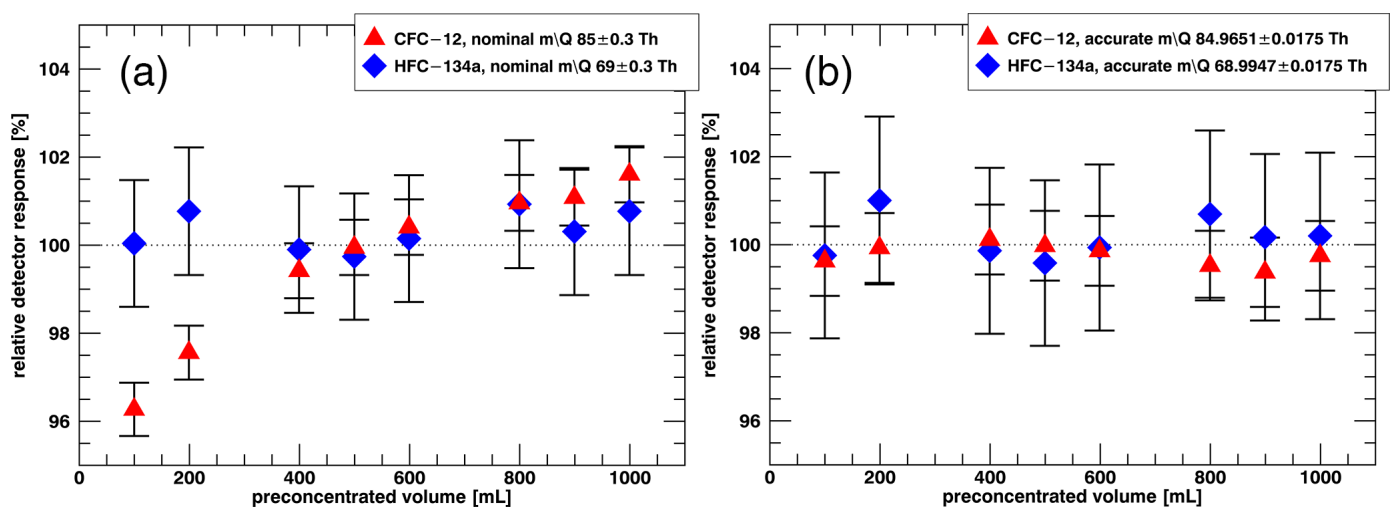

Figure 8. Relative detector responses ( $y$ axis) derived for different preconcentration volumes ( $x$ axis) of the same reference gas. Relative responses were calculated relative to the detector response of calibration points with a preconcentrated volume of $0.5 \mathrm{~L}$. Error bars: 3 -fold measurement precision of the respective substance. (a) Results based on nominal mass data; (b) results based on accurate mass data. While HFC-134a (blue diamonds) does not deviate significantly from linearity in either of the panels, a systematic non-linearity is observed for CFC-12 (red triangles) in (a).

While HFC-134a shows no deviations from the expected linear response within the 3 -fold measurement precision, a systematic deviation from linearity is observed for CFC-12 if the calculation of relative responses is based on nominal mass intensities, i.e. integer mass of the ion serving as quantifier \pm 0.3 Th (Fig. 8a). The mixing ratio of CFC-12 in smaller sample volumes would be systematically underestimated while the mixing ratio in larger volumes would be systematically overestimated. Although most pronounced for CFC-12, this systematic deviation from linearity was also found for four other substances with similar chromatographic peak heights $(0.5 \mathrm{~L}$ preconcentrated volume, peak heights given relative to the peak height of CFC-12): $\mathrm{CH}_{3} \mathrm{Cl}$ (74.5\% relative height), $\mathrm{CFC}-11\left(\mathrm{CCl}_{3} \mathrm{~F}\right.$, $56.7 \%$ relative height $), \mathrm{HCFC}-22\left(\mathrm{CHClF}_{2}, 32.6 \%\right.$ relative height) and $\operatorname{COS}(25.7 \%$ relative height). All substances with peak heights of $\leq \sim 15 \%$ relative to CFC-12 did not reveal a systematic deviation from linearity like e.g. HFC-134a with $10.1 \%$ relative height. For the correlation of chromatographic peak height and the deviation from linearity expressed as the $n$-fold measurement precision, a Spearman rank correlation coefficient of $\rho=+0.78(p<0.0001)$ was found. This suggests that the degree of non-linearity correlates positively with the maximum number of fragment ions formed by ionization of a substance eluting from the GC.

The systematic non-linearity found for the species named above mostly disappears if the calculation of relative responses is based on accurate mass intensities - i.e. the exact ion mass of the ion serving as quantifier $\pm 0.0175 \mathrm{Th}$, as exemplarily shown in Fig. $8 \mathrm{~b}$ for CFC-12. The results for other substances like HFC-134a do not change significantly compared to the results based on nominal mass intensities.

The difference of nominal and accurate mass intensities can possibly be assigned to a (potentially instrument- specific) signal reflection at high intensities, presumably in the high-frequency line between MCP and pre-amplifier or also within the pre-amplifier itself. As illustrated in Fig. 9, a "shoulder" appears to the right of the ion signal. As both results displayed in Fig. 9 are based on chromatograms of the same reference gas, a neighbouring ion signal should appear in both chromatograms ( 0.1 and $1.0 \mathrm{~L}$ preconcentrated volume). The hypothesis of a signal reflection can furthermore be supported by the finding that a longer signal cable between MCP and pre-amplifier moves the "shoulder" further away from the actual signal. As the reflected signal travels through the cable multiple times, the relative offset towards the actual signal is increased if the duration of a single pass-through is increased by a longer cable. This observation is displayed in Figure 10 for the highintensity signal on mass 69 of the $\mathrm{CF}_{3}^{+}$ion from the mass axis calibration substance (see Sect. 2.3 for a description of the calibration pulser).

If signals are summed up over an interval of $\pm 0.3 \mathrm{Th}$ around the integer mass, the area of the artificial "shoulder" is included in the nominal mass intensity, creating a positive offset which increases with the number of ions reaching the detector (i.e. sample volume) according to the results discussed above. Consequently, the response from a larger sample volume is overestimated and the response from a smaller sample volume is underestimated as the comparison is done relative to the response from a fixed sample volume of $0.5 \mathrm{~L}$. The fact that no non-linearities were found below a certain signal height $(\leq \sim 15 \%$ relative to CFC-12 signal height) suggests that the signal reflection becomes insignificant at low intensities. Note that in the example discussed above, we had to use a narrower mass interval to calculate the accurate mass intensity and exclude the reflection $( \pm 0.0175 \mathrm{Th}$ instead of $\pm 0.0250 \mathrm{Th}$ used by default, see Sect. 2.4). 


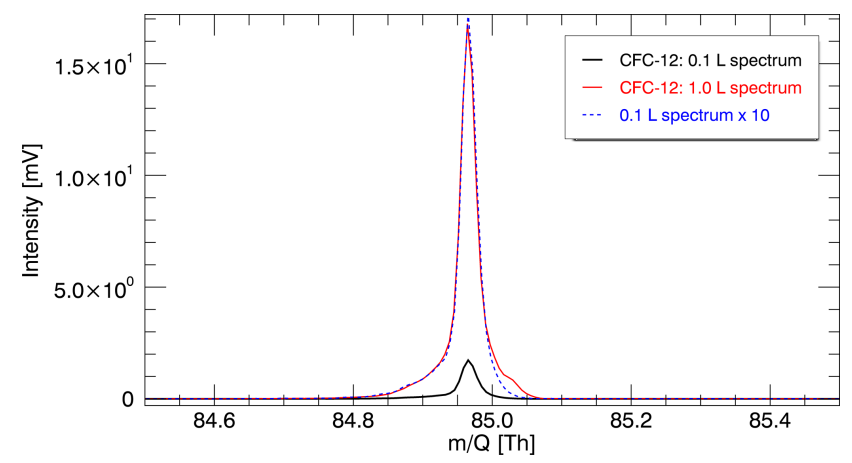

Figure 9. Comparison of $\mathrm{CF}_{2}^{35} \mathrm{Cl}^{+}$signals taken from the chromatographic peak apex of CFC-12. The solid lines in black and red show intensities of a 0.1 and $1.0 \mathrm{~L}$ sample, both from preconcentrations of the same reference gas. Towards high intensities (1.0 L spectrum), a "shoulder" appears to the right of the ion signal, which is not detectable at low intensities $(0.1 \mathrm{~L}$ spectrum). The blue dashed line shows the intensity of the $0.1 \mathrm{~L}$ spectrum multiplied by 10 for comparison. No "shoulder" is visible in this calculated spectrum.

From a practical point of view, the non-linearities observed are problematic if the following conditions are met: (1) the analysis is done with nominal mass intensities and (2) the signal intensity generated by the quantifier ion of a substance reaches a certain level (which has to be determined by dedicated experiments). Condition (2) can also be met for substances like HFC-134a which did not exhibit non-linear behaviour in the experiment described above but might show large variability of mixing ratio in different samples. However, suppression of the non-linearity by the use of accurate mass intensities is possible without a significant decrease in measurement precision (Fig. 8b). Furthermore, the open data format of the used TOFMS does offer many options to correct the non-linearity by exploiting the accurate mass information. Narrow mass intervals is just one straightforward approach and other procedures like a mass peak fitting using prescribed peak shapes or a mathematical deconvolution of signal peak and reflected peak would also be possible.

\subsection{Comparison to reference instrument}

For quality assurance, we compared the instrument to our laboratory GC-QPMS, which showed consistent results with the NOAA network (National Oceanic and Atmospheric Administration) in Hall et al. (2014) and has been used before by Laube et al. (2010), Brinckmann et al. (2012) and Hoker et al. (2015). During the currently ongoing InGOS (Integrated non- $\mathrm{CO}_{2}$ Greenhouse gas Observation System) Halocarbon Round Robin Intercomparison (IHRRI), four ambient air flask samples were analysed on both instruments using the same calibration gas. A relative comparison is therefore not afflicted by calibration gas mixing ratio

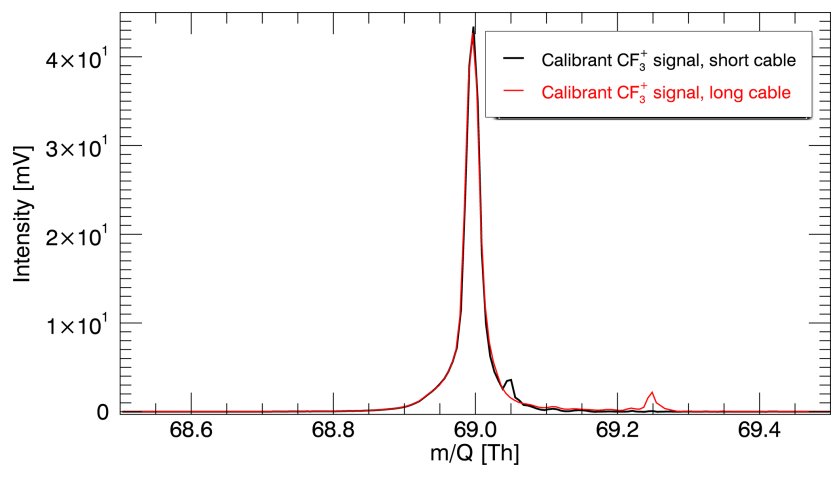

Figure 10. $\mathrm{CF}_{3}^{+}$signals obtained from the mass axis calibration substance (perfluoroperhydrophenanthrene; see also Sect. 2.3), with signal intensity displayed on the $y$ axis and $m / Q$ displayed on the $x$ axis. The signal drawn in black was obtained with a short connection cable between MCP and pre-amplifier (ca. $150 \mathrm{~mm}$ ); the signal drawn in red was obtained with a long cable between MCP and pre-amplifier (ca. $1500 \mathrm{~mm}$ ). No chromatographic run was active at the time of recording. The signal elevation to the right of the actual ion signal is clearly shifted to the right if the signal travel time is increased by a longer cable.

uncertainties or calibration scale differences. Please note that no official IHRRI results have been published at the time of preparation of this paper so we will not name any specific mixing ratios.

Thirty-four substances were analysed on both the GCQPMS and the GC-TOFMS and compared subsequently. One substance, tetrachloroethene $\left(\mathrm{C}_{2} \mathrm{Cl}_{4}\right)$, was excluded from comparison due to contamination issues at the GC-TOFMS (blank residues $>20 \%$ ). The mean absolute deviation over all four samples between both instruments was calculated for each substance. Furthermore, the mean ratio of both instruments over all substances was analysed for each sample to check for systematic deviations. The mean ratio did not deviate significantly from 1 within one standard deviation. An overall systematic deviation between both instruments is therefore not evident.

Figure 11 shows results for the 33 substances compared. A substance-specific error estimate was calculated by Gaussian error propagation of the $1 \sigma$ measurement precision of both instruments. Nineteen of 33 substances $(58 \%)$ are in very good agreement (within 1-fold error) and 12 substances are in good agreement (within 2-fold error) at both instruments, giving a total of $94 \%$ within the 2 -fold error. For only two substances, the differences in mixing ratio lay further apart than the 2-fold error: trichloroethene $\left(\mathrm{C}_{2} \mathrm{HCl}_{3}\right.$, 2.5 -fold error) and methyl chloroform (2.1-fold error). Trichloroethene is systematically elevated in chromatograms of the GC-TOFMS; therefore, a contamination problem similar to tetrachloroethene is likely, however not confirmed by blank residues. A significant difference in methyl chloroform mixing ratio between both instruments is only observed in one sample of the round robin series (likely 


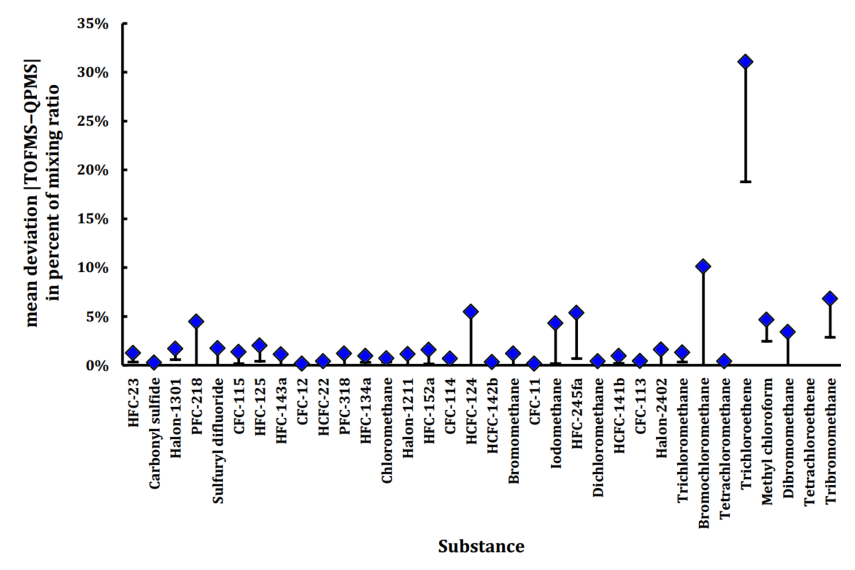

Figure 11. Mean deviation of mixing ratios determined with the GC-QPMS and the GC-TOFMS in the four InGOS round robin flasks. $X$ axis: list of the 33 substances analysed, order based on retention times on the GC-quadrupole MS. $Y$ axis: average absolute deviation of both instruments in [\%]. GC-TOFMS results were derived from accurate mass intensities. Error bars: uncertainty calculated by Gaussian error propagation of the $1 \sigma$ measurement precision of both instruments.

polluted air). Results shown earlier in this work (Sect. 3.3) suggest that the GC-TOFMS could provide better accuracy in the case of methyl chloroform.

\section{Summary and conclusion}

In this work, a newly developed GC-TOFMS system designed for the quantitative analysis of halogenated trace gases was characterized. Besides a state-of-the-art GC and TOFMS, the setup comprises a self-built sample preconcentration unit. It is routinely operated with an adsorption temperature of $-80^{\circ} \mathrm{C}$, but allows $-120^{\circ} \mathrm{C}$ (tested) and depending on the cycle time of cooling and heating even lower adsorption temperatures, without needing a cooling agent like liquid nitrogen. The thermodesorption of the preconcentrated sample directly onto the warm GC column together with a cool-down time back to adsorption temperature of less than $60 \mathrm{~s}$ allows a high cycle time. The combination of automated sample selection, preconcentration and measurement sequencing, as well as the fully accessible data format of the TOFMS, enabled us to gain in-depth understanding of the analytical instrument with focus on the mass spectrometer.

The medium-level mass resolving power of approximately 4000 allows the quantitative separation of e.g. many hydrocarbon fragments from halogenated fragments. This makes the analysis more independent from sample matrix effects and can therefore increase accuracy of quantification. The latter is mandatory for reliable quantification, as needed for many atmospheric halocarbon analyses (attribution of trends, sources etc.). It also gives the instrument an advantage over quadrupole mass spectrometers in chemical identification, although it cannot compete with instruments built specifically for this task with mass resolving powers of multiple tens of thousands. Mass accuracy determined for the characterized instrument was found to support the benefits from the mass resolving power of the instrument in respect to unambiguous fragment identification. The calibrant pulser of the TOFMS was found to be a very valuable innovation as it offers the option to establish automated recalibration of the mass axis.

The mass spectrometer was also found to be very sensitive, especially when using the accurate mass information. This allows for relatively small and easy-to-handle sample sizes of $0.5-1.0 \mathrm{~L}$ and also the early detection of emerging compounds with very low atmospheric mixing ratios in the range of a few ppt to ppq. At the upper end of the concentration range, no saturation effect of the detector was observed for any of the analysed species; the largest preconcentration volume tested was $10.0 \mathrm{~L}$ corresponding to about $5.2 \mathrm{ppb}$ (ca. $25.5 \mathrm{ng}$ ) of the highest concentrated halocarbon CFC-12.

A measure for the measurement precision needed for atmospheric trace gas analysis, here mainly halocarbons, is the capability of resolving atmospheric variability and trends. One of the most challenging tasks is the attribution of atmospheric trends of major long-lived halocarbons, at least on yearly base. The instrument is capable of classifying most sample mixing ratios into the yearly trend of the respective substances (Carpenter et al., 2014) based on a single measurement. There are only a few exceptions of substances with very small trends, e.g. CFC-114 with $-0.2 \% \mathrm{yr}^{-1}\left(-0.01 \mathrm{ppt} \mathrm{yr}^{-1}\right)$.

Instrument non-linearities were found to be negligible for the low and medium mixing ratio range analysed $(<150 \mathrm{ppt}$ at $0.5 \mathrm{~L}$ preconcentration volume). At higher concentration levels, significant non-linearities were found, in positive correlation with signal intensity. These non-linearities could be suppressed by setting narrow mass intervals around mass signals and thereby excluding artificially elevated parts of the signal. At this time, it is not clear whether this issue is specific to our instrument or affects a series of EI-TOFMS. A hardware solution is ongoing work at Tofwerk and also in cooperation with us to fully understand and solve the problem.

Overall, the instrument was found to be very well suited for the quantitative analysis of halocarbons in air, also supported by the results of a comparison to a reference instrument. A big step forward was made compared to common quadrupole and TOFMS with low resolving power $\leq 1000$. The availability of accurate mass information at medium mass resolving power has proven to be very valuable due to the simplified substance identification, the gain in sample matrix independence and measurement accuracy and also in respect to the exclusion of non-linearities induced by the detection system of the MS. Within the described 
field of application, both the general limitations being low dynamic range and non-linearity of TOFMS seem to be overcome by the Tofwerk instrument. Together with the always present high-sensitivity full mass range, these aspects make TOFMS in general an ideally suited method for digital air archiving. This work is only focused on halocarbons in atmospheric air samples, but in principle there is much more information in the chromatograms recorded with full mass range. We have just started to look into other substance classes like hydrocarbons and the GC-TOFMS data look very promising for future (re-)analysis of many more substances than discussed here.

Acknowledgements. We would like to thank the Deutsche Forschungsgemeinschaft (DFG) for funding the project under research grant EN367/12-1, L. Merkel and the workshop of that institute for technical drawings as well as component construction and M. Vollmer (Laboratory for Air Pollution/Environmental Technology of the Swiss EMPA) for providing substance identification samples. Furthermore, we thank Tofwerk AG, especially Y. Papadopoulos for support with the TOFMS and M. Gonin for proof-reading the paper. Finally our thanks go to two anonymous reviewers for their constructive comments.

Edited by: F. Stroh

\section{References}

Arnold, T., Mühle, J., Salameh, P. K., Harth, C. M., Ivy, D. J., and Weiss, R. F.: Automated measurement of nitrogen trifluoride in ambient air, Anal. Chem., 84, 4798-4804, 2012.

Bassford, M. R., Simmonds, P. G., and Nickless, G.: An automated system for near-real-time monitoring of trace atmospheric halocarbons, Anal. Chem., 70, 958-965, 1998.

Bonk, T. and Humeny, A.: MALDI-TOF-MS analysis of protein and DNA, Neuroscientist, 7, 6-12, 2001.

Brinckmann, S., Engel, A., Bönisch, H., Quack, B., and Atlas, E.: Short-lived brominated hydrocarbons - observations in the source regions and the tropical tropopause layer, Atmos. Chem. Phys., 12, 1213-1228, doi:10.5194/acp-12-1213-2012, 2012.

Carpenter, L. J., Reimann, S., Burkholder, J. B., Clerbaux, C., Hall, B. D., Hossaini, R., Laube, J. C., and Yvon-Lewis, S. A.: Ozone-Depleting Substances (ODSs) and other gases of interest to the Montreal Protocol, in: Scientific Assessment of Ozone Depletion: 2014, Global Ozone Research and Monitoring Project - Report No. 55, 416 pp., World Meteorological Organization, Geneva, Switzerland, 2014.

Clemons, C. A. and Altshuller, A. P.: Responses of electron-capture detector to halogenated substances, Anal. Chem., 38, 133-136, 1966.

Coles, J. N. and Guilhaus, M.: Resolution limitations from detector pulse width and jitter in a linear orthogonal-acceleration time-offlight mass spectrometer, J. Am. Soc. Mass Spectrom., 5, 772778, doi:10.1016/1044-0305(94)80010-3, 1994.

DeCarlo, P. F., Kimmel, J. R., Trimborn, A., Northway, M. J., Jayne, J. T., Aiken, A. C., Gonin, M., Fuhrer, K., Horvath, T.,
Docherty, K. S., Worsnop, D. R., and Jimenez, J. L.: Field-deployable, high-resolution, time-of-flight aerosol mass spectrometer, Anal. Chem., 78, 8281-8289, 2006.

Emteborg, H., Tian, X., Ostermann, M., Berglund, M. and Adams, F. C.: Isotope ratio and isotope dilution measurements using axial inductively coupled plasma time of flight mass spectrometry, J. Anal. Atom. Spectrom., 15, 239-246, 2000.

Farman, J. C., Gardiner, B. G., and Shanklin, J. D.: Large losses of total ozone in Antarctica reveal seasonal $\mathrm{ClO}_{x} / \mathrm{NO}_{x}$ interaction, Nature, 315, 207-210, 1985.

Grant, A., Yates, E. L., Simmonds, P. G., Derwent, R. G., Manning, A. J., Young, D., Shallcross, D. E., and O'Doherty, S.: A five year record of high-frequency in situ measurements of non-methane hydrocarbons at Mace Head, Ireland, Atmos. Meas. Tech., 4, 955-964, doi:10.5194/amt-4-955-2011, 2011.

Graus, M., Müller, M., and Hansel, A.: High resolution PTR-TOF: quantification and formula confirmation of VOC in real time, J. Am. Soc. Mass Spectr., 21, 1037-1044, 2010.

Grimsrud, E. P. and Rasmussen, R. A.: Survey and analysis of halocarbons in the atmosphere by gas chromatography-mass spectrometry, Atmos. Environ., 9, 1014-1017, 1975.

Guilhaus, M.: Special feature: Tutorial, principles and instrumentation in time-of-flight mass spectrometry, physical and instrumental concepts, J. Mass Spectrom., 30, 1519-1532, 1995.

Hall, B. D., Engel, A., Mühle, J., Elkins, J. W., Artuso, F., Atlas, E., Aydin, M., Blake, D., Brunke, E.-G., Chiavarini, S., Fraser, P. J., Happell, J., Krummel, P. B., Levin, I., Loewenstein, M., Maione, M., Montzka, S. A., O’Doherty, S., Reimann, S., Rhoderick, G., Saltzman, E. S., Scheel, H. E., Steele, L. P., Vollmer, M. K., Weiss, R. F., Worthy, D., and Yokouchi, Y.: Results from the International Halocarbons in Air Comparison Experiment (IHALACE), Atmos. Meas. Tech., 7, 469-490, doi:10.5194/amt7-469-2014, 2014.

Hoker, J., Obersteiner, F., Bönisch, H., and Engel, A.: Comparison of GC/time-of-flight MS with GC/quadrupole MS for halocarbon trace gas analysis, Atmos. Meas. Tech., 8, 2195-2206, doi:10.5194/amt-8-2195-2015, 2015.

IUPAC: Compendium of Analytical Nomenclature (the "Orange Book”), Blackwell Science, Ltd., Oxford, UK, 1998.

IUPAC: Compendium of Chemical Terminology - Gold Book, available at: http://goldbook.iupac.org/PDF/goldbook.pdf (last access: 14 September 2015), 2014.

Keller, C. A., Hill, M., Vollmer, M. K., Henne, S., Brunner, D., Reimann, S., O'Doherty, S., Arduini, J., Maione, M., Ferenczi, Z., Haszpra, L., Manning, A. J., and Peter, T.: European emissions of halogenated greenhouse gases inferred from atmospheric measurements, Environ. Sci. Technol., 46, 217-225, 2011.

Kerwin, R. A., Crill, P. M., Talbot, R. W., Hines, M. E., Shorter, J. H., Kolb, C. E., and Harriss, R. C.: Determination of atmospheric methyl bromide by cryotrapping-gas chromatography and application to soil kinetic studies using a dynamic dilution system, Anal. Chem., 68, 899-903, 1996.

Laube, J. C., Kaiser, J., Sturges, W. T., Bönisch, H., and Engel, A.: Chlorine isotope fractionation in the stratosphere, Science, 329, 1167, doi:10.1126/science.1191809, 2010.

Laube, J. C., Hogan, C., Newland, M. J., Mani, F. S., Fraser, P. J., Brenninkmeijer, C. A. M., Martinerie, P., Oram, D. E., 
Röckmann, T., Schwander, J., Witrant, E., Mills, G. P., Reeves, C. E., and Sturges, W. T.: Distributions, long term trends and emissions of four perfluorocarbons in remote parts of the atmosphere and firn air, Atmos. Chem. Phys., 12, 4081-4090, doi:10.5194/acp-12-4081-2012, 2012.

Lee, J. M., Sturges, W. T., Penkett, S. A., Oram, D. E., Schmidt, U., Engel, A., and Bauer, R.: Observed stratospheric profiles and stratospheric lifetimes of HCFC-141b and HCFC-142b, Geophys. Res. Lett., 22, 1369-1372, 1995.

Lunt, M. F., Rigby, M., Ganesan, A. L., Manning, A. J., Prinn, R. G., O'Doherty, S., Muhle, J., Harth, C. M., Salameh, P. K., Arnold, T., Weiss, R. F., Saito, T., Yokouchi, Y., Krummel, P. B., Steele, L. P., Fraser, P. J., Li, S., Park, S., Reimann, S., Vollmer, M. K., Lunder, C., Hermansen, O., Schmidbauer, N., Maione, M., Arduini, J., Young, D., and Simmonds, P. G.: Reconciling reported and unreported HFC emissions with atmospheric observations, P. Natl. Acad. Sci. USA, 112, 59275931, 2015.

Maione, M., Giostra, U., Arduini, J., Belfiore, L., Furlani, F., Geniali, A., Mangani, G., Vollmer, M. K., and Reimann, S.: Localization of source regions of selected hydrofluorocarbons combining data collected at two European mountain stations, Sci. Total Environ., 391, 232-240, 2008.

Midgley, T.: From the Periodic Table to production, Ind. Eng. Chem., 29, 241-244, 1937.

Miller, B. R., Weiss, R. F., Salameh, P. K., Tanhua, T., Greally, B. R., Muhle, J., and Simmonds, P. G.: Medusa: a sample preconcentration and GC/MS detector system for in situ measurements of atmospheric trace halocarbons, hydrocarbons, and sulfur compounds, Anal. Chem., 80, 1536-1545, 2008.

Molina, M. J. and Rowland, F. S.: Stratospheric sink for chlorofluoromethanes: chlorine atomc-atalysed destruction of ozone, Nature, 249, 810-812, 1974.

Mühle, J., Ganesan, A. L., Miller, B. R., Salameh, P. K., Harth, C. M., Greally, B. R., Rigby, M., Porter, L. W., Steele, L. P., Trudinger, C. M., Krummel, P. B., O’Doherty, S., Fraser, P. J., Simmonds, P. G., Prinn, R. G., and Weiss, R. F.: Perfluorocarbons in the global atmosphere: tetrafluoromethane, hexafluoroethane, and octafluoropropane, Atmos. Chem. Phys., 10, 5145-5164, doi:10.5194/acp-10-5145-2010, 2010.

Ravishankara, A. R., Turnipseed, A. A., Jensen, N. R., Barone, S., Mills, M., Howard, C. J., and Solomon, S.: Do hydrofluorocarbons destroy stratospheric ozone?, Science, 263, 71-75, 1994.

Rowland, A. and Holcombe, J. A.: Evaluation and correction of isotope ratio inaccuracy on inductively coupled plasma time-offlight mass spectrometry, Spectrochim. Acta B, 64, 35-41, 2009.
Sala, S., Bönisch, H., Keber, T., Oram, D. E., Mills, G., and Engel, A.: Deriving an atmospheric budget of total organic bromine using airborne in situ measurements from the western Pacific area during SHIVA, Atmos. Chem. Phys., 14, 6903-6923, doi:10.5194/acp-14-6903-2014, 2014.

Simmonds, P. G., O’Doherty, S., Nickless, G., Sturrock, G. A., Swaby, R., Knight, P., Ricketts, J., Woffendin, G., and Smith, R.: Automated gas chromatograph/mass spectrometer for routine atmospheric field measurements of the CFC replacement compounds, the hydrofluorocarbons and hydrochlorofluorocarbons, Anal. Chem., 67, 717-723, 1995.

Simmonds, P. G., Derwent, R. G., Manning, A. J., McCulloch, A., and O'Doherty, S.: USA emissions estimates of $\mathrm{CH}_{3} \mathrm{CHF}_{2}$, $\mathrm{CH}_{2} \mathrm{FCF}_{3}, \mathrm{CH}_{3} \mathrm{CF}_{3}$ and $\mathrm{CH}_{2} \mathrm{~F}_{2}$ based on in situ observations at Mace Head, Atmos. Environ., 104, 27-38, 2015.

Stohl, A., Kim, J., Li, S., O’Doherty, S., Mühle, J., Salameh, P. K., Saito, T., Vollmer, M. K., Wan, D., Weiss, R. F., Yao, B., Yokouchi, Y., and Zhou, L. X.: Hydrochlorofluorocarbon and hydrofluorocarbon emissions in East Asia determined by inverse modeling, Atmos. Chem. Phys., 10, 3545-3560, doi:10.5194/acp-10-3545-2010, 2010.

Velders, G. J. M., Madronich, S., Clerbaux, C., Derwen, R., Grutter, M., Hauglustaine, D., Incecik, S., Ko, M., Libre, J.-M., Nielsen, O. J., Stordal, F., and Zhu, T.: Chemical and radiative effects of halocarbons and their replacement compounds, in: IPCC/TEAP 2005 - Safeguarding the Ozone Layer and the Global Climate System: Issues Related to Hydrofluorocarbons and Perfluorocarbons, Cambridge University Press, Cambridge, UK, 133-180, 2005.

Vollmer, M. K., Miller, B. R., Rigby, M., Reimann, S., Mühle, J., Krummel, P. B., O’Doherty, S., Kim, J., Rhee, T. S., Weiss, R. F., Fraser, P. J., Simmonds, P. G., Salameh, P. K., Harth, C. M., Wang, R. H. J., Steele, L. P., Young, D., Lunder, C. R., Hermansen, O., Ivy, D., Arnold, T., Schmidbauer, N., Kim, K.R., Greally, B. R., Hill, M., Leist, M., Wenger, A., and Prinn, R. G.: Atmospheric histories and global emissions of the anthropogenic hydrofluorocarbons HFC-365mfc, HFC-245fa, HFC-227ea, and HFC-236fa, J. Geophys. Res., 116, D08304, doi:10.1029/2010jd015309, 2011.

Vollmer, M. K., Reimann, S., Hill, M., and Brunner, D.: First observations of the fourth generation synthetic halocarbons HFC-1234yf, HFC-1234ze(E), and HCFC-1233zd(E) in the atmosphere, Environ. Sci. Technol., 49, 2703-2708, 2015. 